\title{
Effect of Time on Dynamic Shear Modulus of Selected Cohesive Soil of One Section of Express Way No. S2 in Warsaw
}

\author{
Wojciech SAS, Katarzyna GABRYŚ, and Alojzy SZYMAŃSKI \\ Faculty of Civil- and Environmental Engineering, \\ Warsaw University of Life Sciences (SGGW), Warsaw, Poland; \\ e-mails: wojciech_sas@sggw.pl, \\ katarzyna_gabrys@sggw.pl (corresponding author), ajozy_szymanski@sggw.pl
}

\section{Abstract}

Several researches published comprehensive reports on dynamic soil properties of cohesive soils, in which many of them outlined, i.e., key factors affecting the dynamic shear modulus. For cohesive soils, the modulus at small strains $\left(\gamma<10^{-3} \%\right)$ is, first of all, a function of void ratio and effective confining stress. For clays, however, secondary time effects and clay mineralogy (fabric and structure) also appear to be important. The influence of confinement of laboratory-prepared as well as naturally deposited clays consists in an increase of shear modulus logarithmically as a function of time. In this paper, the effect of duration of the various confining pressures on dynamic shear modulus $(G)$ of selected cohesive soils from Warsaw area was evaluated. Shear modulus was determined on the basis of resonant column tests, at low and high shearing strain amplitudes. It is shown that the calculated shear modulus is time-dependent; during approximately first 1000 minutes of consolidation, the moduli increased by almost $50 \%$. Moreover, it is characterized by two phases: an initial one results from primary consolidation and a second one, which occurs after the end of primary consolidation, herein about 16-17 hours, and is called "long-term time effect". This effect was found also for modulus at higher shearing strains $\left(\gamma>10^{-3} \%\right.$, e.g., $\left.3 \times 10^{-3} \%, 5 \times 10^{-3} \%, 8 \times 10^{-3} \%, 2 \times 10^{-2} \%\right)$.

Key words: dynamic shear modulus, time-dependency, cohesive soil. 


\section{INTRODUCTION}

The dynamic shear modulus is an important property of soil, especially from the viewpoint of evaluating wave propagation in soil and, on the basis of it, receiving access to dynamic response of embankments, pavements, foundations, etc. (Tezcan et al. 2009). Road subgrades or shallow foundations are continuously loaded cyclically by various machines, vehicles (cars, trains), and other factors (Khosravi et al. 2010, Sidorova and Voznesensky 2010). Earthquakes, pile driving, explosions also put the load to water-saturated or unsaturated, fine- and coarse-grained or cohesive soil deposits (Vucetic and Dobry 1991).

The dynamic shear modulus of soil in the range of strain amplitude less than $10^{-4}$ is referred to as the maximum or small-strain dynamic shear modulus, denoted by the symbol $G_{\max }$. Many studies have been conducted to find and properly characterized factors which affect this parameter. The main elements that have an effect on $G_{\max }$ include: shear strain amplitude $(\gamma)$, mean effective confining stress $\left(\sigma_{m}^{\prime}, p^{\prime}\right)$, soil type and plasticity index (PI). Other factors which influence the small-strain dynamic shear modulus, but appear to be less important, include: frequency of loading, number of loading cycles, void ratio, degree of saturation, overconsolidation ratio, grain characteristics, and many others. Additionally, it has been suggested that through grouping the test data by geology some less essential component may be also taken into account (Zhang et al. 2005, Markowska-Lech et al. 2013).

One other factor, i.e., duration of the confining pressure, is of fundamental importance in laboratory determination of shear modulus as well. The aspect of effect of time on soil stiffness is, unfortunately, often either misunderstood or neglected. This overlooking can have negative impact on the interpretation of the test data and results, which may lead to some failure in deriving maximum benefit from a research program (Anderson and Stokoe 1978).

In this paper, some key information about the effect of time, under fix pressure conditions, on shear modulus of selected cohesive soils from area of Warsaw is presented. Previous studies on this subject are briefly reviewed here. Testing procedures are shortly described as well. Finally, examples of the results from laboratory tests are given, which illustrate the significance of the effect of time on soil stiffness.

\section{SECONDARY TIME EFFECTS}

Several investigators have shown that time-dependency is a significant parameter affecting the dynamic properties of soils (Zavoral 1990). The effect of confinement duration at the unchanging pressure conditions was first observed in 1961 (Richart 1962). In the next years, other researchers reported 
the followings: during experiments at a constant confining pressure, shear modulus at the low strain amplitude (below 0.001\%) increased with time of specimen confinement (e.g., Lawrence 1965, Afifi and Richart 1973, Anderson and Woods 1976). These general observations led to more detailed studies of artificially prepared soil samples and the growth of their stiffness with time. The last tests at a long-lasting pressure on undisturbed specimens of cohesive and loose soils showed similarities. Time-dependent behaviour is a characteristic feature of natural soils too (Anderson and Stokoe 1978).

For most soils, the time-dependency at low strain level can be described by an initial phase, while the shear modulus changes instantly with the logarithm of time, as presented in Fig. 1. This early stage results from changes in the void ratio during the primary consolidation process. Therefore, this phase is related to primary consolidation. During the second part, the value of modulus rises nearly linearly with the logarithm of time, which is caused probably by strengthening of physical-chemical bonds in cohesive soils and by an increase in particle-particle contacts in cohesionless soils. The latter stage refers to the so-called "long-term time effect" that occurs only after the primary consolidation course has been completed.

There are two methods to explain the long-term time effect. The result of time-dependency can be, on the one hand, expressed in an absolute sense, i.e., as a coefficient of shear modulus increase with time $\left(I_{G}\right)$

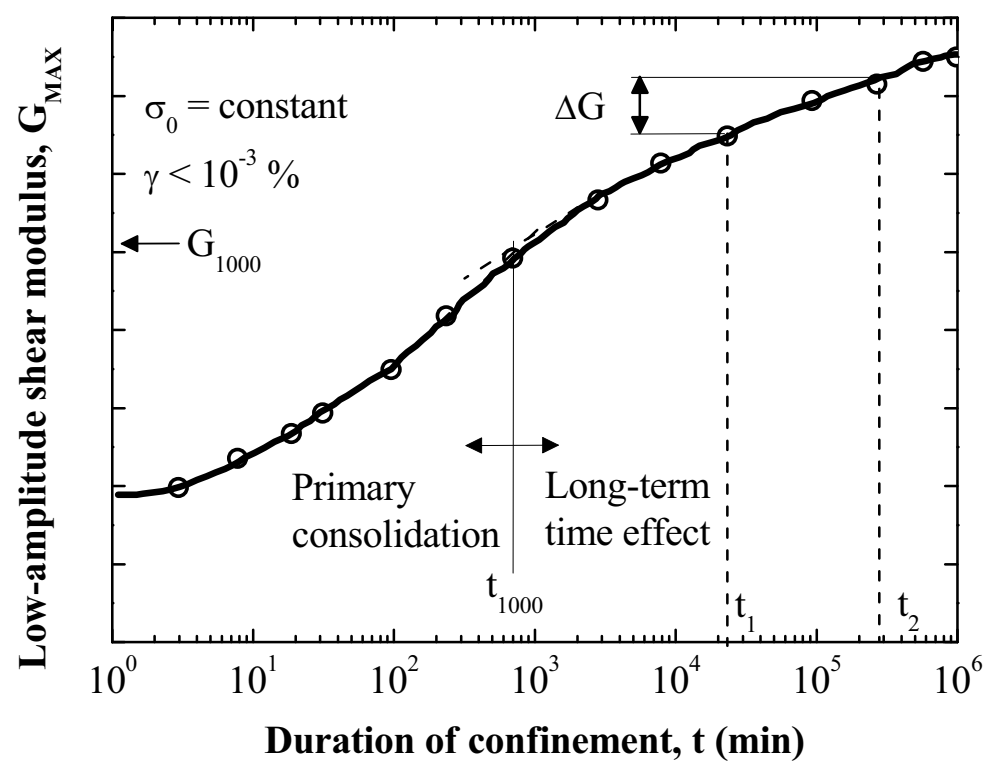

Fig. 1. Division of stages in low-amplitude shear modulus-time response (after Anderson and Stokoe 1978). 


$$
I_{G}=\frac{\Delta G}{\log _{10}\left(\frac{t_{2}}{t_{1}}\right)},
$$

where $\Delta G$ is the increase in low-amplitude shear modulus in logarithmic cycle of time, and $t_{1}, t_{2}$, are times after primary consolidation (Fig. 1.)

In a numerical manner, for one logarithmic cycle of time, $I_{G}$ equals $\Delta G$.

The other way of interpretation of the long-term time effect is, in relative terms, by using the normalized shear modulus with time $\left(N_{G}\right)$ according to the formula

$$
N_{G}=\frac{I_{G}}{G_{1000}},
$$

where $G_{1000}$ is the modulus measured after 1000 minutes of constant confining pressure, which must be after completion of primary consolidation.

In general, parameter $N_{G}$ becomes greater when the mean grain size decreases (Afifi and Richart 1973). However, more logical relationship between the rate of secondary modulus $\left(N_{G}\right)$ and plasticity index (PI) was proposed by Kokusho et al. (1982). The plasticity index (PI) is a measure of the plasticity of a soil; it is the size of the range of water contents for which the soil exhibits plastic properties. PI is the difference between the liquid limit and the plastic limit (PI = LL-PL). PI reflects the chemical activity of clay minerals; therefore, with growing plasticity index there is an increase of $N_{G}$, amounting to as much as $25 \%$ per log cycle of time.

In most cases, the measured $N_{G}$ value for clays ranges between 0.05 and 0.25 . For sands, parameter $N_{G}$ varies between 0.01 and 0.03 and rises when the soil gets finer, as presented by Mesri et al. (1990). Jamiolkowski and Manassero (1996) reported that silica sand samples reached the value of $N_{G}$ from 0.001 to 0.03 , sand samples with $50 \%$ of mica 0.039 , whereas carbonate sand samples 0.05-0.12. On the basis of the experiments of Howie et al. (2002), the rate of increase of the shear modulus with time for very loose carbonate sands grows along with the stress level. Isotropic stress state arrived at a slower rate of increase in stiffness (Soga 2005).

\section{LABORATORY TESTS}

To study the time dependent increase in dynamic shear modulus, a set of resonant column tests was performed. The material investigated belongs to a natural cohesive soil formation in the Warsaw area, originally taken from the region of the express way No. S2 (around the road embankment No. WD-18). It is a clayey sand, clSa (Eurocode 7), with index properties listed in Table 1. The samples were taken from a depth of around $2.0 \mathrm{~m}$ selected carefully 
Index parameters of specimens

\begin{tabular}{|c|c|c|}
\hline \multirow{2}{*}{ Parameter } & \multicolumn{2}{|c|}{ Value } \\
\hline & Clayey sand (1) & Clayey sand (2) \\
\hline$w_{L} \quad[\%]$ & 36.80 & 35.21 \\
\hline$w_{P} \quad[\%]$ & 13.76 & 11.43 \\
\hline$I_{P} \quad[\%]$ & 23.04 & 23.78 \\
\hline$G_{S} \quad[-]$ & 2.68 & 2.68 \\
\hline$w \quad[\%]$ & 14.43 & 14.20 \\
\hline$\rho \quad\left[\mathrm{kg} / \mathrm{m}^{3}\right]$ & 2.12 & 2.16 \\
\hline
\end{tabular}

Explanations: $w_{L}$ is the liquid limit, $w_{P}$ the plastic limit, $I_{P}$ the plastic index, $G_{S}$ the specific gravity, $w$ the water content, and $\rho$ is the mass density.

considering the uniformity of the soils structure, its physical properties, and its double-phase. Only one type of undisturbed soil samples was obtained, namely tube samples, with the inner diameter of the tube of about $80 \mathrm{~mm}$. Tubes were carefully and gently pressed into the pre-drilled holes. All the samples were sealed and stored in a humidity room until needed.

The resonant column apparatus successfully used in this research was manufactured by British company GDS Instruments Ltd (GDS 2010). The device is presented in detail by Sas and Gabryś (2012), and Gabryś et al. (2013). Just to sum up briefly, the object of the resonant column technique is to vibrate the soil-top-cap system at first-mode resonance. This resonance is defined as the frequency at which the maximum top-cap motion is obtained during a sweep of frequencies, here mostly starting around $30 \mathrm{~Hz}$. At the first-mode resonance, material in a cross-section at every elevation vibrates in phase with the top of the sample. Shear wave velocity, and then shear modulus are determined based on the system's constants, size, weight, and shape of the tested specimen (GDS 2010).

Table 2 summarized the authors' experiments during which the effect of long-term confinement on low-amplitude dynamic shear modulus was evaluated. Time effect was recorded for clayey sand samples over a wide range of confining pressures, $\sigma_{0}$ from 335 up to $685 \mathrm{kPa}$, as well as a broad variety in shear moduli on low amplitude, $G_{\max }$ from 15 up to $175 \mathrm{MPa}$. The shear modulus for investigated samples was monitored at various times during the consolidation period. This is generally involved taking measurements well beyond the time required for the end of primary consolidation in order to find the time dependent increase at a constant effective pressure. 
The tests conditions

\begin{tabular}{|c|c|c|c|c|c|c|}
\hline $\begin{array}{l}\text { Soil } \\
\text { type }\end{array}$ & $\begin{array}{l}\text { Specimen } \\
\text { type }\end{array}$ & $\begin{array}{c}\text { Mean } \\
\text { effective } \\
\text { stress } \\
{[\mathrm{kPa}]} \\
\end{array}$ & $\begin{array}{c}\text { Confining } \\
\text { pressure } \\
{[\mathrm{kPa}]}\end{array}$ & $\begin{array}{c}\text { Shear modulus } \\
\text { on low amplitude } \\
\text { [MPa] }\end{array}$ & $\begin{array}{c}I_{G} \\
{[\mathrm{MPa}]}\end{array}$ & $\begin{array}{l}N_{G} \\
{[\%]}\end{array}$ \\
\hline \multirow{5}{*}{$\begin{array}{c}\text { Clayey } \\
\text { sand } \\
(1)\end{array}$} & \multirow{5}{*}{ undisturbed } & 45 & 335 & $15-30 *$ & - & - \\
\hline & & 90 & 380 & $30-55^{*}$ & - & - \\
\hline & & 135 & 425 & $40-90^{* *}$ & 20.44 & 27.25 \\
\hline & & 180 & 470 & $80-95 *$ & - & - \\
\hline & & 225 & 515 & $80-110^{*}$ & - & - \\
\hline \multirow{3}{*}{$\begin{array}{c}\text { Clayey } \\
\text { sand } \\
(2)\end{array}$} & \multirow{3}{*}{ undisturbed } & 180 & 550 & $80-170 * *$ & 6.81 & 4.72 \\
\hline & & 270 & 640 & $155-175^{* *}$ & 30.51 & 21.83 \\
\hline & & 315 & 685 & $170-175^{* *}$ & 6.42 & 5.14 \\
\hline
\end{tabular}

*) measurements conducted during primary consolidation,

**) measurements conducted during and after the end of primary consolidation.

\section{EXPERIMENTAL RESULTS}

\subsection{Low-amplitude test procedure}

In time-dependent resonant column tests, dynamic shear modulus was defined at various times after application of different confining pressures. The recording time was usually: $1,10,20,30,45,60$, and 90 minutes after the selected pressure was employed, as well as just after the completion of primary consolidation. In this study, strains reached the level below $0.001 \%$, and therefore it was a low-amplitude test. Figure 2 presents some examples of the results for the variation of shear modulus at changing mean effective stress. The duration of vibration at shearing strain levels of this kind is negligible (Anderson and Stokoe 1978). It should not be essential if the specimen is continuously or only seconds under vibration. The effect of time in Fig. 2 is noticeable for all mean effective stresses $\left(p^{\prime}\right)$. An increase in values of dynamic shear modulus is about $4-6 \%$, at each time step when the measurements were performed. Generally, from the beginning till the end of primary consolidation, the rise in shear modulus may be as high as $50 \%$. Figure 3 is also an illustration showing low-amplitude shear modulus growth in time at various stress level. On the basis of this diagram it can be seen in detail how the parameter $G_{\max }$ grows over time; we see at which point of time the increase in values of $G_{\max }$ was recorded to be the largest. In the first 10-20 minutes, the rise of $G_{\max }$ is quite rapid and relatively high in comparison with the next measurements; then this growth gets stabilized until the final phase of the test, when it achieves the biggest values, up to even $25 \mathrm{MPa}$ for $p^{\prime}=90 \mathrm{kPa}$ and $p^{\prime}=225 \mathrm{kPa}$. 


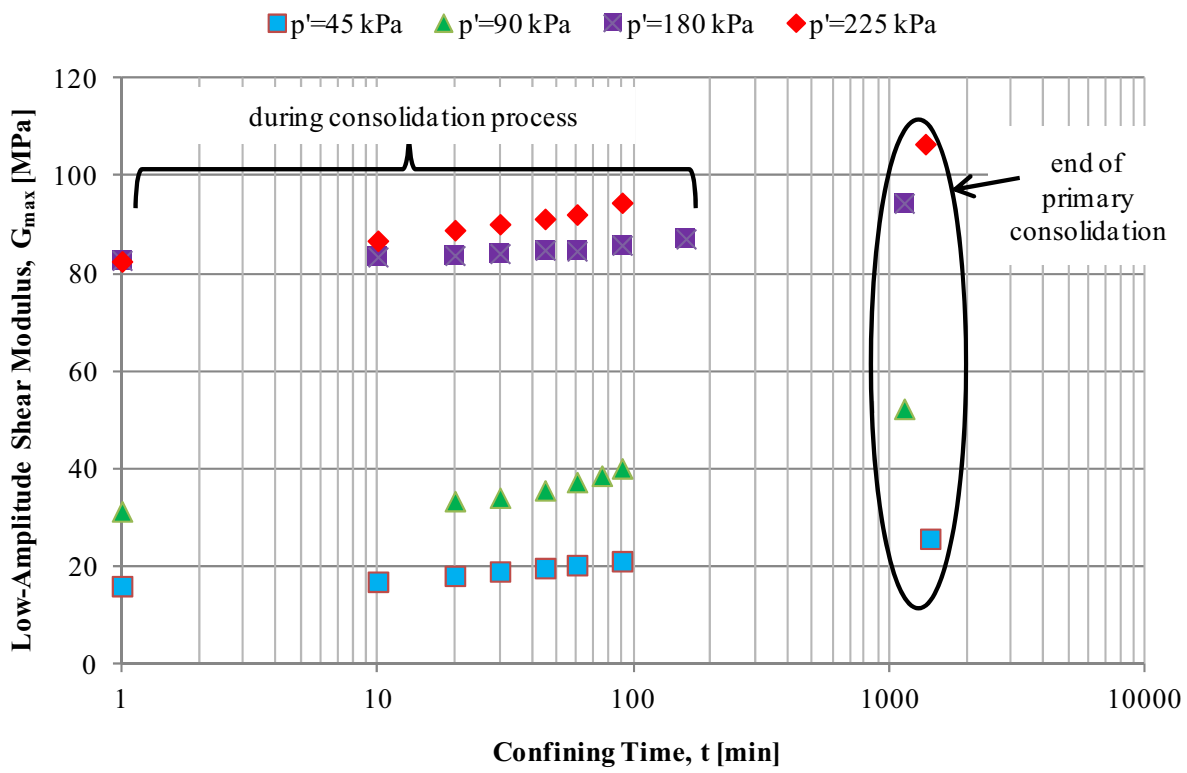

Fig. 2. Time-dependent shear modulus of clayey sand samples from Warsaw area under different stress conditions.

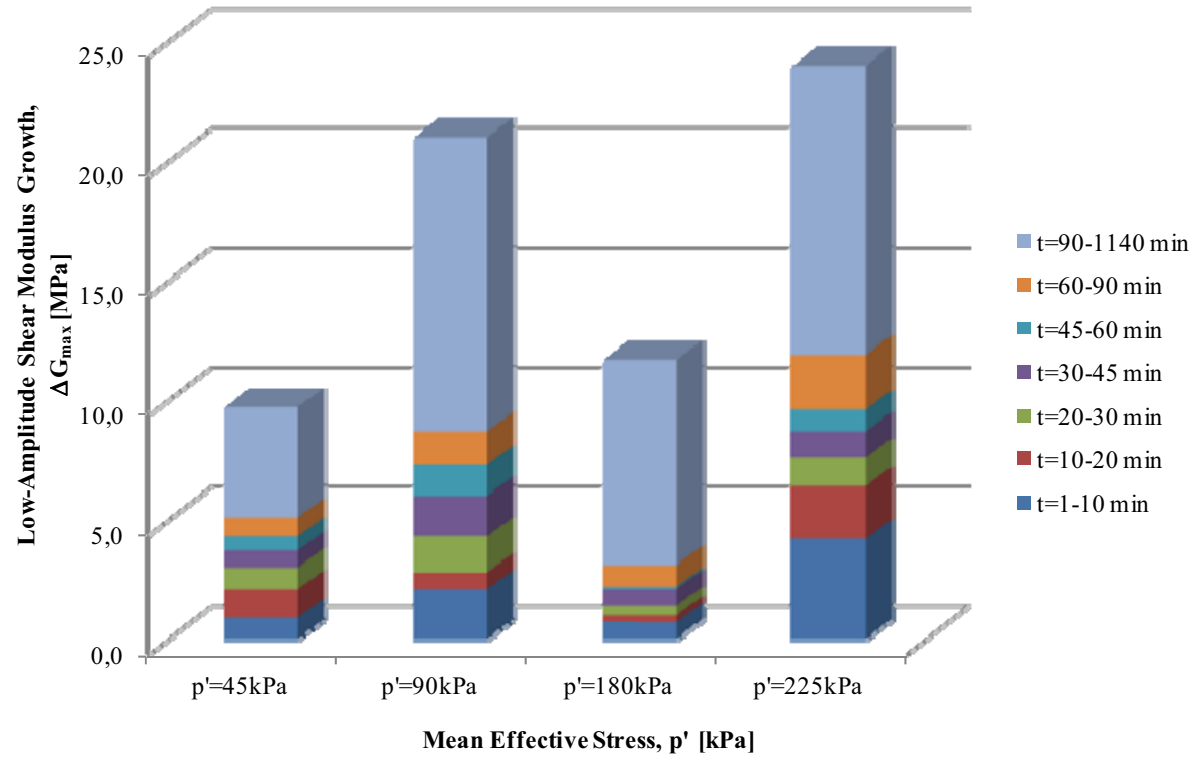

Fig. 3. Low-amplitude shear modulus growth in time at various stress levels. 


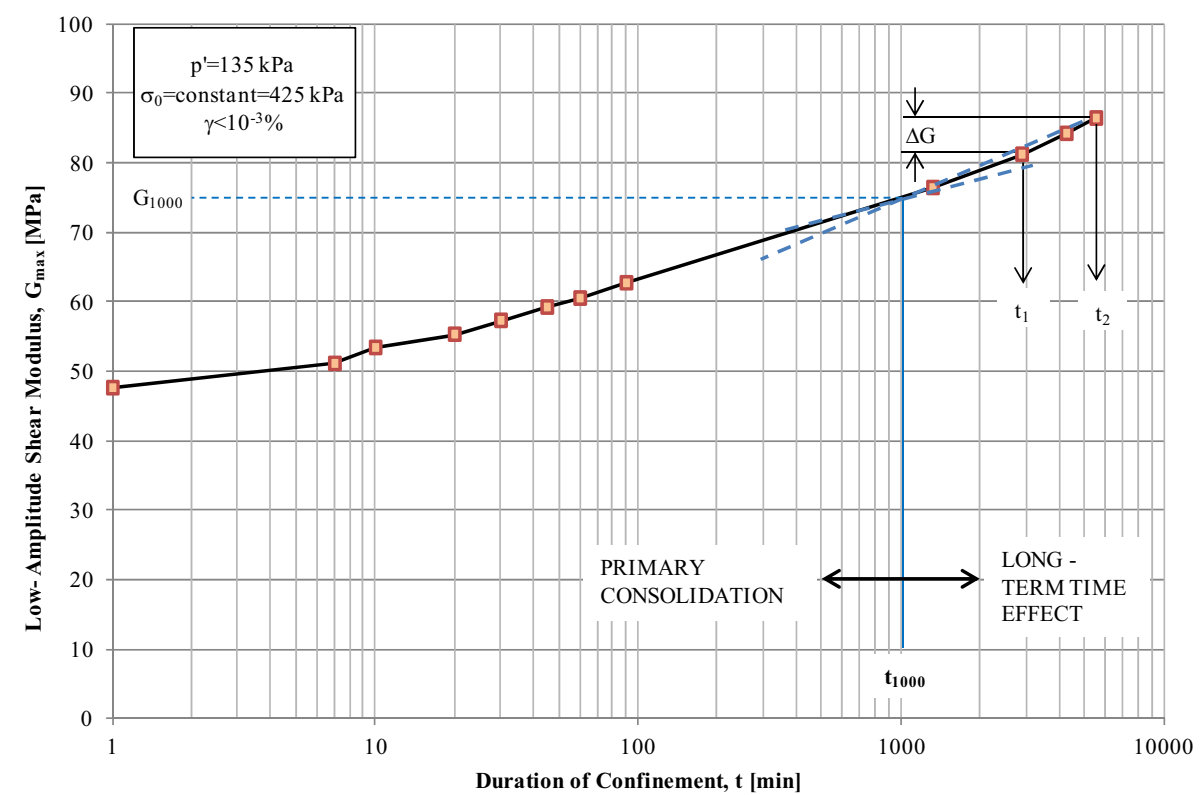

Fig. 4. Low-amplitude test sequence for a clayey sand sample and an example of the determination of $I_{G}$ parameter.

During the whole low-amplitude test, the conditions with a possibility of drainage were maintained. It was not necessary to close the valves due to dynamic oscillations, because the level of deformation was too low to generate the excess pore-water pressure.

The measurements at low-amplitude for certain samples were performed after the end of primary consolidation was detected. On the basis of this method, the parameter $I_{G}$ could be well evaluated. The procedure of determining an increase in low-amplitude shear modulus in time for a clayey sand sample is illustrated in Fig. 4.

Two distinct phases of modulus-time response are evident in Fig. 5. In order to better demonstrate this division into two stages of changes in $G_{\max }$, the authors propose to introduce a new variable, called $t_{G s t a b}$, which will indicate the end of primary consolidation and the beginning of the long-term time effect. The parameter $t_{G s t a b}$ will be the moment when changes in the value of low-amplitude of shear modulus start to be smaller, the values themselves are more stable, and their increase is low and nearly linear. This new parameter does not necessarily coincide with $t_{1000}$, which means the time at 1000 minutes of the constant confining pressure and, basically, in most cases, the end of primary consolidation.

In order to obtain dynamic shear modulus, resonant frequencies are first converted to shear wave velocities by using elastic theory formulas. The cor- 


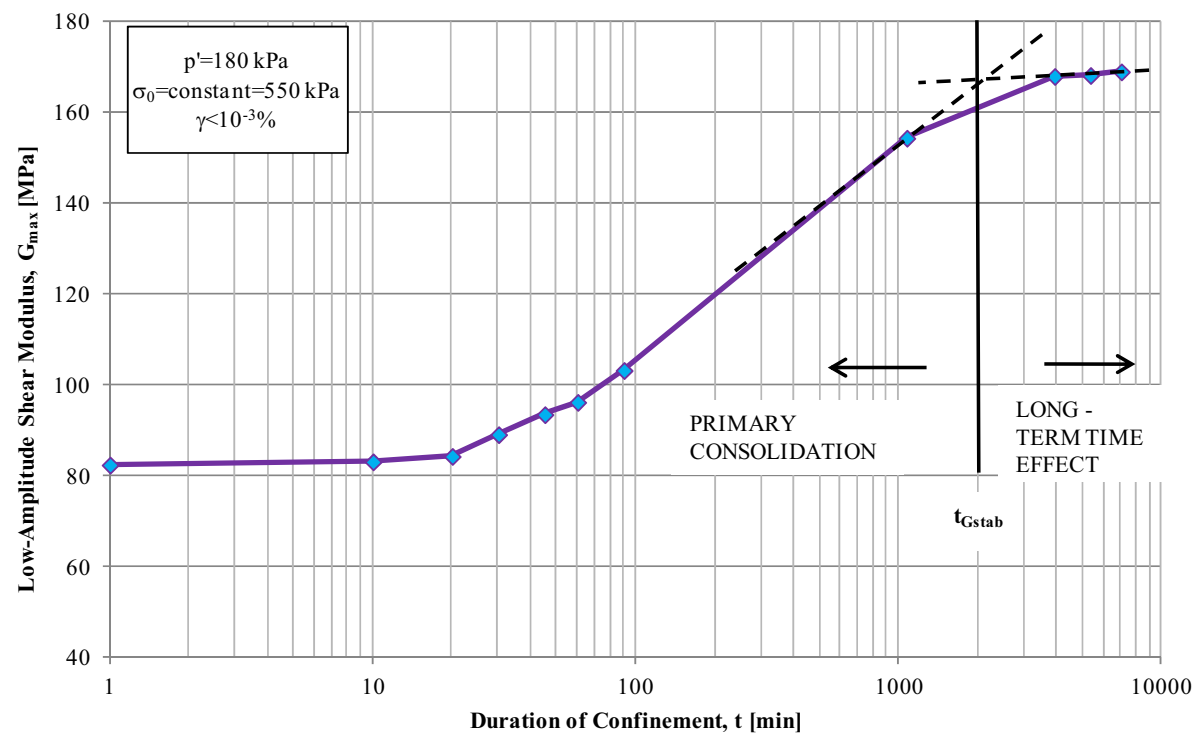

Fig. 5. Another illustration of the two phases of modulus-time response curve with the proposal to introduce a new parameter $t_{G s t a b}$.

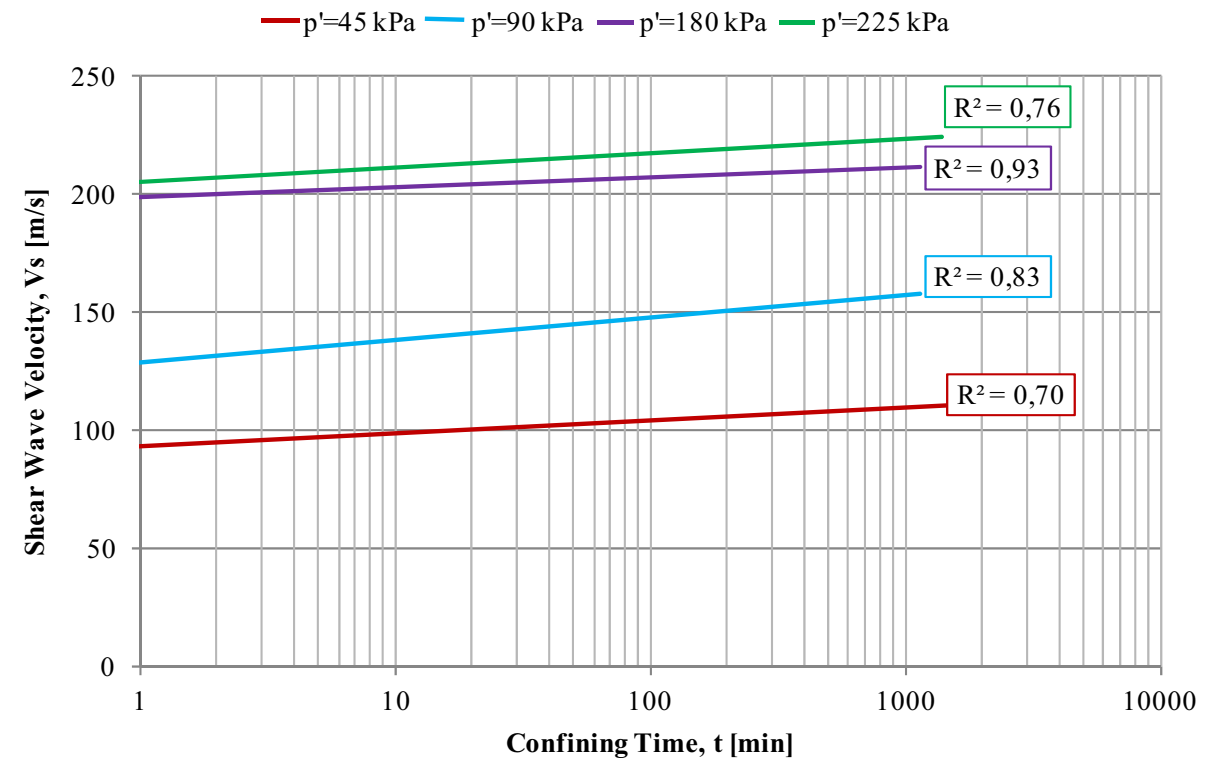

Fig. 6. Variation in shear wave velocity with time for clayey sand samples from Warsaw area under different stress conditions, ranging from 45 up to $225 \mathrm{kPa}$. 


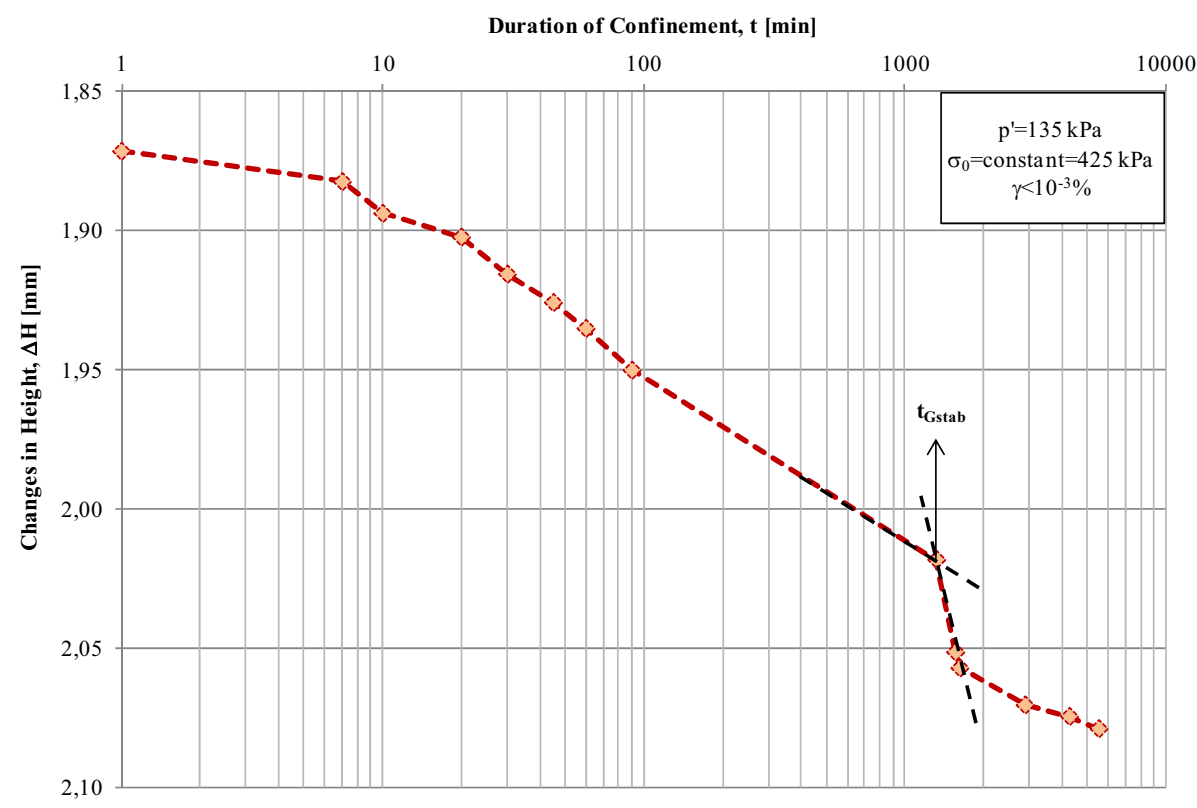

Fig. 7. Height changes with time for a clayey sand sample under constant confining pressure, i.e., $p^{\prime}=135 \mathrm{kPa}$.

rect calculations should consider the proper values of specimen height, weight, and volume at the measurement time. Figure 6 presents the variation of shear wave velocity as a function of logarithm of time at a fix pressure. With increasing time and increasing mean effective stress, the shear wave velocity rises as well, mainly from 1 until $3 \mathrm{~m} / \mathrm{s}$ in a particular time period. The increase of $V_{S}$ can be assumed linear (Fig. 6). The regression line, however, only for mean effective stress $\left(p^{\prime}\right)$ of 90 and $180 \mathrm{kPa}$ approximates well the real data points; the coefficient of determination $\left(R^{2}\right)$ amounts to more than 0.8 (strong correlation). In the other two cases, assuming fitting by linear function as well, the authors received some positive correlations, but not a perfect one $\left(R^{2}\right.$ is at the level of 0.7). In Figure 7 changes of specimen height are shown. As an example of the change in sample height during resonant column test, the measurements at the confining pressure $\sigma_{0}=425 \mathrm{kPa}$ and mean effective stress $p^{\prime}=135 \mathrm{kPa}$ were chosen.

\subsection{High-amplitude test procedure}

After the process of primary consolidation was finished, the measurements of dynamic shear modulus at shearing strains bigger than $0.001 \%$ were performed. During primary consolidation it is not recommended to vibrate specimens at higher stain amplitude due to the indefinite effective stress 
conditions, as well as the possibility of variation in pore-water pressure and soil structure in the meantime. In the authors' researches, high-amplitude tests were conducted straight away after primary consolidation, but also some time later, up to 1 or 2 days. It was important to have the long-term time effect well defined at low-amplitude of shearing strain.

In this study, high-amplitude measurements were performed in several steps by increasing the amplitude of vibration in torsional mode. During these tests, in order to excite the electromagnetic field and induce a wave propagating through the examined material, the corresponding coil voltage values were applied, from the value of 0.1 up to $1.0 \mathrm{~V}$, with a step of $0.1 \mathrm{~V}$ (Table 3). Figure 8 portrays the results from high-amplitude test sequence. Between all measurements there was always some rest time, about one minute.

Table 3

The tests conditions during high-amplitude measurements

\begin{tabular}{|c|c|c|c|c|c|c|}
\hline $\begin{array}{l}\text { Soil } \\
\text { type }\end{array}$ & $\begin{array}{l}\text { Speci- } \\
\text { men } \\
\text { type }\end{array}$ & $\begin{array}{c}\text { Mean } \\
\text { effective } \\
\text { stress } \\
{[\mathrm{kPa}]}\end{array}$ & $\begin{array}{c}\text { Time } \\
\text { of the end } \\
\text { of primary } \\
\text { consolidation } \\
\text { [min] }\end{array}$ & $\begin{array}{c}\text { High shearing strain } \\
{[\%]}\end{array}$ & $\begin{array}{c}\text { Shear } \\
\text { modulus } \\
\text { on high } \\
\text { ampli- } \\
\text { tude } \\
{[\mathrm{MPa}]}\end{array}$ & $\begin{array}{l}\text { Corre- } \\
\text { sponding } \\
\text { coil } \\
\text { voltage } \\
{[\mathrm{V}]}\end{array}$ \\
\hline \multirow{5}{*}{$\begin{array}{l}\text { Clayey } \\
\text { sand } \\
\text { (1) }\end{array}$} & \multirow{5}{*}{$\begin{array}{l}\text { undis- } \\
\text { turbed }\end{array}$} & 45 & 14 & $2.5 \mathrm{E}$ & $20-5$ & \multirow{8}{*}{$0.2-1.0$} \\
\hline & & 90 & & $1.3 \mathrm{E}-02-1.4 \mathrm{E}-01$ & $42-14$ & \\
\hline & & 135 & 1320 & $8.9 \mathrm{E}-03-8.9 \mathrm{E}-02$ & $76-24$ & \\
\hline & & 180 & 1140 & $7.5 \mathrm{E}-03-6.6 \mathrm{E}-02$ & $84-35$ & \\
\hline & & 225 & 1380 & $6.7 \mathrm{E}-03-5.4 \mathrm{E}-02$ & $97-44$ & \\
\hline \multirow{3}{*}{$\begin{array}{l}\text { Clayey } \\
\text { sand } \\
\text { (2) }\end{array}$} & \multirow{3}{*}{$\begin{array}{l}\text { undis- } \\
\text { turbed }\end{array}$} & 180 & 1070 & $4.8 \mathrm{E}-03-5.4 \mathrm{E}-02$ & $115-51$ & \\
\hline & & 270 & & $2.0 \mathrm{E}-03-2.9 \mathrm{E}-02$ & $171-102$ & \\
\hline & & 315 & 1380 & $2.0 \mathrm{E}-03-2.7 \mathrm{E}-02$ & $173-119$ & \\
\hline
\end{tabular}

After the studies on high-amplitude dynamic shear modulus were completed, the specimens remained under constant confining pressure, with drainage and low-amplitude modulus monitored with time (Fig. 9). It is visible in Fig. 9 that low-amplitude shear modulus had initially a different value, i.e., smaller than that reached before the high-amplitude sequence. The observed decrease in dynamic shear modulus is temporary and lasts only until the low-amplitude modulus regains with time the value forecasted by the long-term time effect. If this does not happen, it may mean a permanent alteration of the specimen, which cannot be longer used in the tests.

A number of studies were carried out to show that long-term modulus increase occurs not only at low but also at intermediate strain level (Fig. 10). 


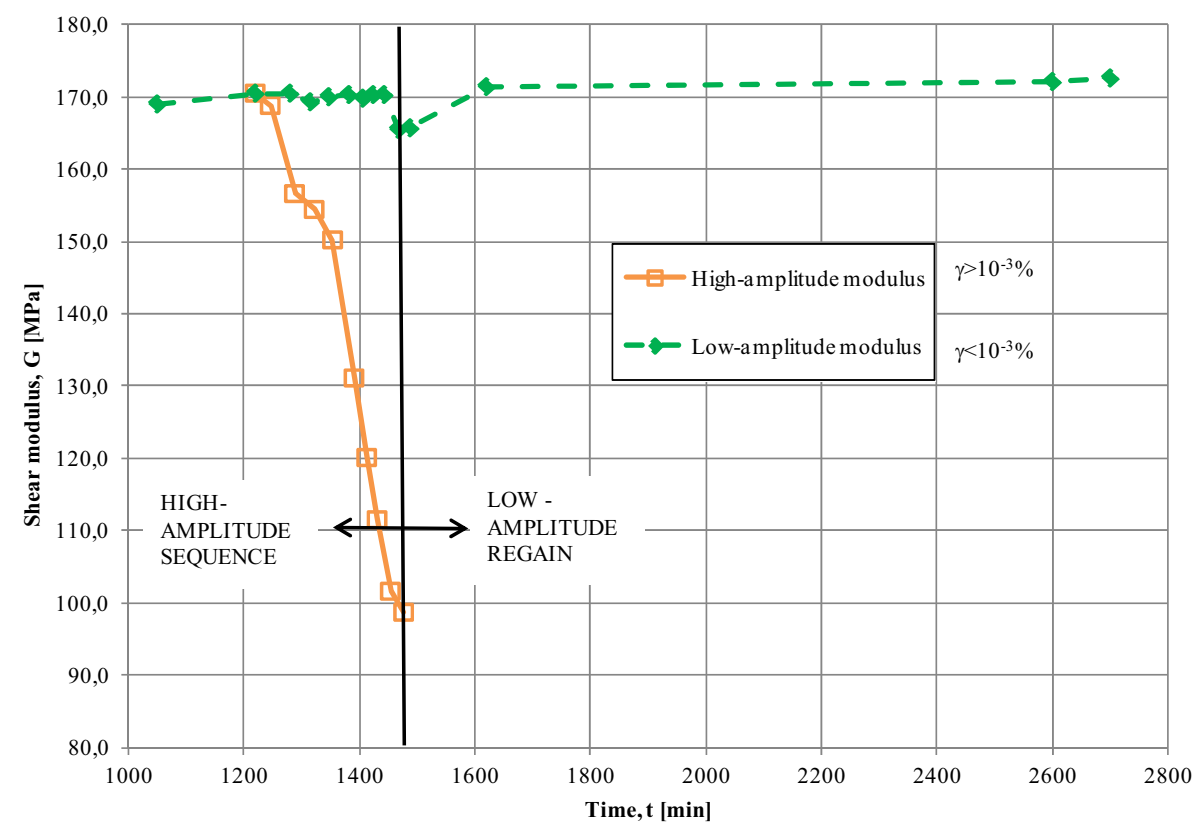

Fig. 8. High-amplitude test sequence (when shearing strain level $\gamma>10^{-3} \%$ ) for a clayey sand sample obtained on the basis of laboratory tests.

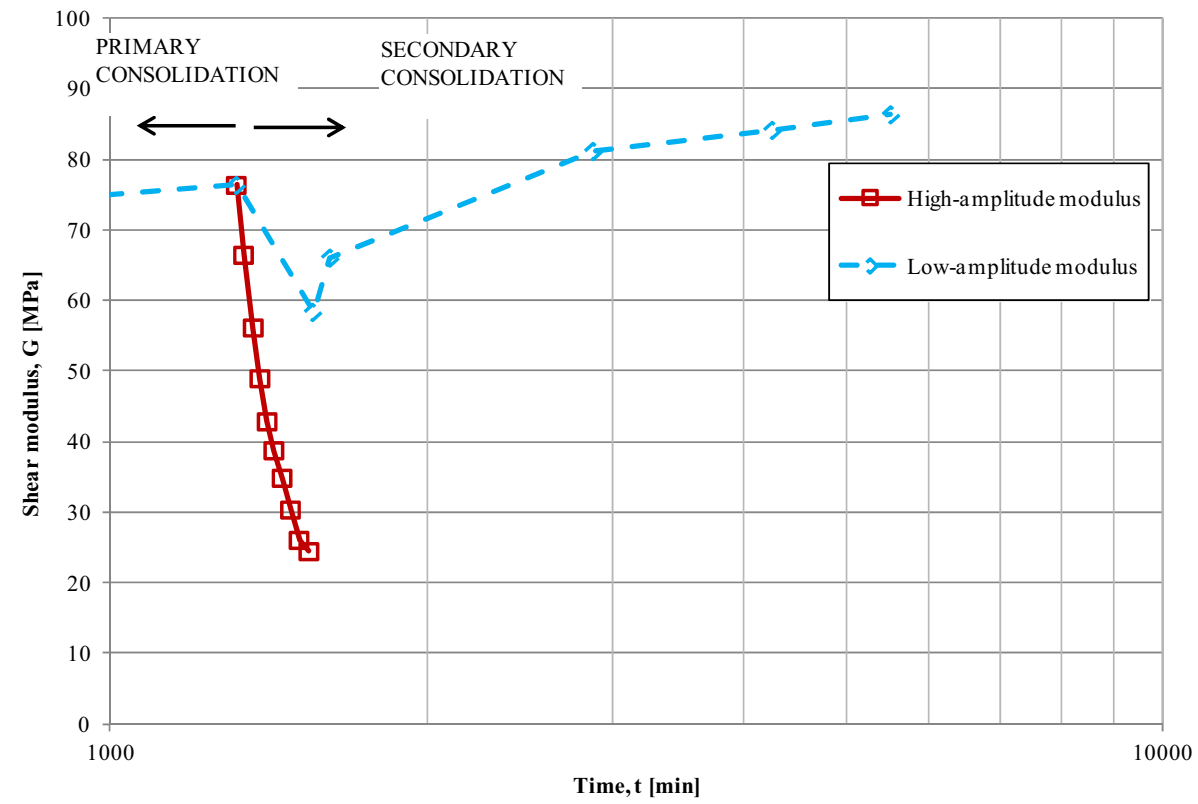

Fig. 9. Changes of high-amplitude and low-amplitude modulus with time and a temporary decrease in dynamic shear modulus. 


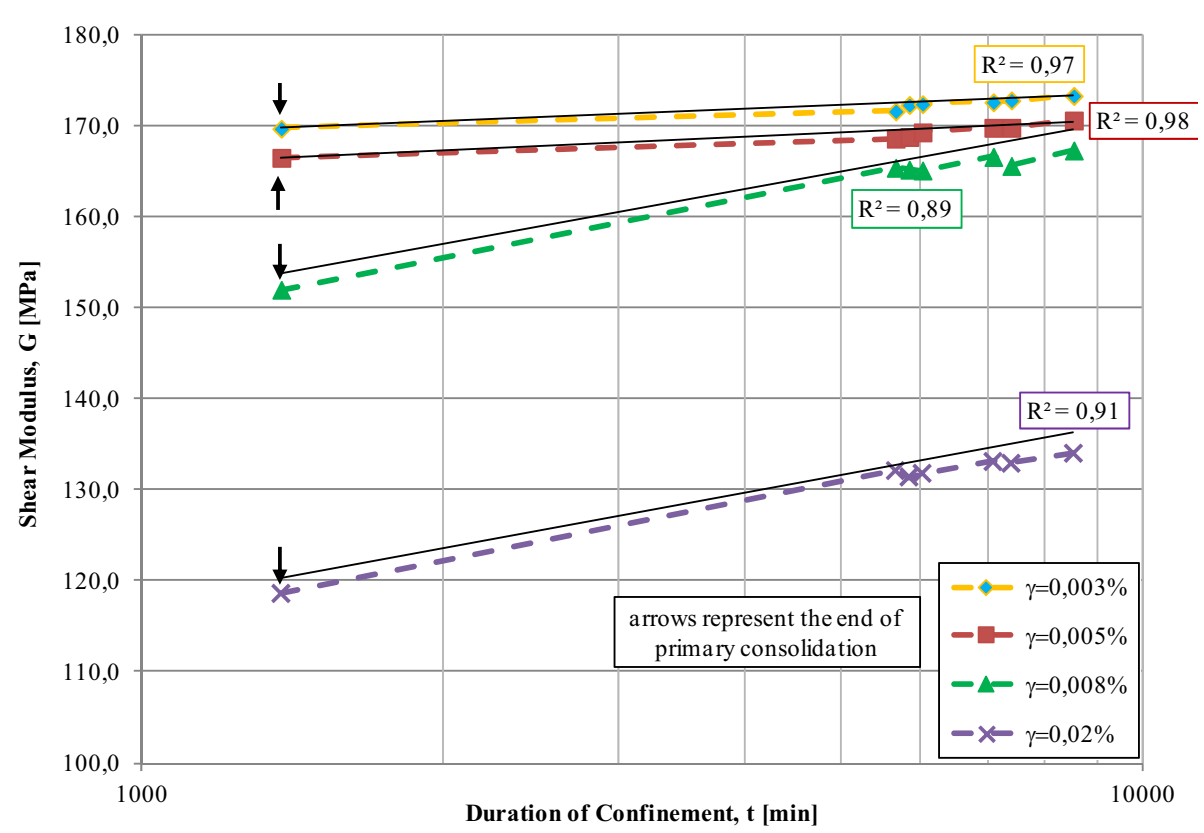

Fig. 10. Time-dependent shear modulus at high shearing strain amplitude (shearing strain values $\gamma$ ranging from $3 \times 10^{-3} \%$ up to $2 \times 10^{-2} \%$ ).

The authors' researches confirm tests of other scientists (Anderson and Stokoe 1978) that at shearing strain level between 0.001 and $0.1 \%$ the dynamic shear modulus grows with time, and this increase is linear; the linear regression line represents well the real data $\left(R^{2}\right.$ at least equal to 0.9$)$. The increase in values of dynamic shear modulus measured at high shearing strain amplitude is about $4 \mathrm{MPa}$ for strain level $\gamma=0.003-0.005 \%$ and around $15 \mathrm{MPa}$ for strain level $\gamma=0.008-0.02 \%$ during the studies. In the main, from the end of primary consolidation until the end of measurement time, the rise in shear modulus may be as high as $6-23 \%$. Some general similarity between the growth with time in low- and high-amplitude shear modulus can be observed. Thus, it might be concluded that factors which have an influence on low-amplitude modulus time response affect the high-amplitude modulus time response as well.

\section{SUMMARY AND CONCLUSIONS}

The behaviour of soil stiffness with time is of fundamental importance both in planning as well as in executing a laboratory testing program. Determination of shear modulus-time response and its proper understanding can be essential for prediction of in situ shear modulus based on the laboratory tests. 
The authors of this paper tried to show this significance of the effect of confinement duration at a constant pressure on the magnitude of shear modulus of a selected cohesive soil from the capital of Poland while performing experiments in resonant column apparatus. This attempt is particularly important due to the lack of such information in the respect of Polish soils.

In summary, according to the literature and data presented in this article, the following conclusions can be drawn:

- Dynamic shear modulus of selected cohesive soil from Warsaw area varies with time of confinement at a fixed level of pressure.

- There are two phases which characterize the time-dependent response of shear modulus at low shearing strains (less than $0.001 \%$ ). These are: an initial phase which occurs because of primary consolidation, and a second phase during which the modulus increases nearly linearly with the logarithm of time. The latter stage is referred to as "long-term time effect".

- The authors suggest the introduction of a new variable, $t_{G s t a b}$, as a moment which will be a boundary between the two phases, as described above (Fig. 5).

- At intermediate strain level (from 0.001 to $0.1 \%$ ) a rise in shear modulus with time is noticeable as well. This increase in high-amplitude modulus is rather slightly less than that which occurs at low-amplitude shearing strains. This growth is exactly around $2 \%$ for shearing strain equal to $3 \times 10^{-3} \%$ and $5 \times 10^{-3} \%$, as well as approximately $10 \%$ for shearing strain equal to $8 \times 10^{-3} \%$ and $2 \times 10^{-2} \%$.

- The measurements of shear modulus at shearing strain above $0.001 \%$ should be performed as described by the authors in Subsection 4.2. Lowamplitude modulus can be used as a reference value in order to define some possible permanent changes in specimens when high-amplitude tests are performed.

The authors of this paper would like to emphasize that the role of the researchers is to point out the values and the variability of soil stiffness, whereas the role of the designers is to choose the right parameters for the proper designing and planning of engineering constructions. It is necessary therefore to keep effective cooperation between the engineers and the designers, from the beginning of the construction design and while considering various construction work schemes. Although geotechnical activities are defined by Eurocode 7 (EN 1997), there is no detailed description of laboratory experiments of the type presented in this article. Perhaps, this is due to some difficulties relating to the determination of the dynamic shear modulus and its further application by the designers. 


\section{References}

Afifi, S.S., and F.E. Richart Jr. (1973), Stress-history effects on shear modulus of soils, Soils Found. 13, 1, 77-95, DOI: 10.3208/sandf1972.13.77.

Anderson, D.G., and K.H. Stokoe II (1978), Shear modulus: A time-dependent soil property. In: Dynamic Geotechnical Testing, ASTM Special Tech. Publ. No. 654, American Society for Testing and Materials, Baltimore, 66-90.

Anderson, D.G., and R.D. Woods (1976), Time-dependent increase in shear modulus of clay, J. Geotech. Eng. Div. ASCE 102, 5, 525-537.

EN (1997), Eurocode 7: Geotechnical Design - General Rules, European Prestandard ENV.

Gabryś, K., W. Sas, and A. Szymański (2013), Resonant column apparatus as a device for dynamic testing of cohesive soils, Prz. Nauk. Inż. Ksztalt. Środ. 59, 3-13 (in Polish).

GDS (2010), The GDS Resonant Column System Handbook (Version 2.2.2010), Geotechnical Digital Systems Instruments Co., London.

Howie, J.A., T. Shozen, and Y. P. Vaid (2002), Effect of ageing on stiffness of very loose sand, Can. Geotech. J. 39, 1, 149-156, DOI: 10.1139/T01-085.

Jamiolkowski, M., and N. Manassero (1996), The role of in situ testing in geotechnical engineering - thoughts about the future. In: C. Craig (ed.), Advances in Site Investigation Practice, Thomas Telford Publ., London, 929-951.

Khosravi, A., M. Ghayoomi, J. McCartney, and H.-Y. Ko (2010), Impact of effective stress on the dynamic shear modulus of unsaturated sand. In: D.O. Fratta, A.J. Puppala, and B. Muhunthan (eds.), Proc. GeoFlorida 2010: Advances in Analysis, Modelling \& Design, American Society of Civil Engineers, 410-419, DOI: 10.1061/41095(365)38.

Kokusho, T., Y. Yoshida, and Y. Esashi (1982), Dynamic properties of soft clay for wide strain range, Soils Found. 22, 4, 1-18, DOI: 10.3208/sandf1972. 22.4_1.

Lawrence, F.V. Jr. (1965), Ultrasonic shear wave velocities in sand and clay, Res. Rep. No. 23, Massachusetts Institute of Technology, Cambridge, USA.

Markowska-Lech, K., M. Lech, M. Bajda, and A. Szymański (2013), Small strain stiffness in overconsolidated Pliocene clays, Ann. Warsaw Univ. Life Sci. $S G G W$ 45, 2, 169-181, DOI: 10.2478/sggw-2013-0014.

Mesri, G., T.W. Feng, and J.M. Benak (1990), Postdensification penetration resistance of clean sands, J. Geotech. Eng. 116, 7, 1095-1115, DOI: 10.1061/ (ASCE)0733-9410(1990)116:7(1095).

Richart, F.E. Jr. (1962), Closure of "Foundation Vibrations", Trans. ASCE 127, 1, 918-926.

Sas, W., and K. Gabryś (2012), Laboratory measurement of shear stiffness in resonant column apparatus, Acta Sci. Pol. - Architectura 11, 4, 29-39. 
Sidorova, A.I., and E.A. Voznesensky (2010), Estimation of additional foundation settlements caused by dynamic loading in urban areas, Acta Geophys. 58, 1, 126-142, DOI: 10.2478/s11600-009-0040-7.

Soga, K. (2005), Lecture 3: Time effects observed in granular materials, SocioEnvironmental Engineering, COE Hokkaido University, Hokkaido, Japan, http://www.eng.hokudai.ac.jp/COE-area/workshop/pdf/05feb_lec_soga3. pdf.

Tezcan, S.S., Z. Ozdemir, and A. Keceli (2009), Seismic technique to determine the allowable bearing pressure for shallow foundations in soils and rocks, Acta Geophys. 57, 2, 400-412, DOI: 10.2478/s11600-008-0077-z.

Vucetic, M., and R. Dobry (1991), Effect of soil plasticity on cyclic response, J. Geotech. Eng. ASCE 117, 1, 89-107, DOI: 10.1061/(ASCE)0733-9410 (1991)117:1(89).

Zavoral, D. (1990), Dynamic properties of an undisturbed clay from resonant column tests, M.Sc. Thesis, Department of Civil Engineering, The University of British Columbia, Vancouver, Canada.

Zhang, J., R.D. Andrus, and H. Juang (2005), Normalized shear modulus and material damping ratio relationships, J. Geotech. Geoenviron. Eng. ASCE 131, 4, 453-464, DOI: 10.1061/(ASCE)1090-0241(2005)131:4(453).

Received 14 October 2013

Received in revised form 26 March 2014

Accepted 16 April 2014 